\title{
GETTING CURSED OUT FOR SOCIAL JUSTICE: NOTES ON HANDLING VERBAL ASSAULTS WITH HUMANITY
}

\author{
DARRICK SMITH ${ }^{1}$ \\ ${ }^{1}$ University of San Francisco, Leadership Studies, School of Education, 2130 Fulton Street, San \\ Francisco, CA 94117-1080, USA. ORCID: 0000-0002-8106-5273,Email: dsmith13@usfca.edu
}

ABSTRACT: A national dialogue on school discipline has now reemerged in the United States as many educators struggle with how to maintain a balance of cultural responsiveness and high expectations when addressing student transgressions on their campuses. While the field of child development, counseling psychology, and communications pose theoretical responses to such dilemmas, this article aims specifically to address the procedural challenges of dealing with verbal abuse from students and adults. Through the lens of a social justice educator, the author offers practical, humanizing steps that are intended to help secondary school educators engage with students in a way that emphasizes boundaries, respect, and reflection for students and adults alike.

KEYWORDS: social justice, education system, discipline, trust, power

\section{INTRODUCTION}

This article seeks to address the phenomenon of student-to-adult verbal conflict which occurs in schools throughout the United States. Data has shown for well over a decade previous that in addition to the near 800,000 reported victimizations that students experience each year in American schools, there exists a dynamic in which teachers being threatened with injury (elementary $=11 \%$, secondary $=9 \%$,) or physically assaulted at a (elementary $=9 \%$, secondary $=2 \%$ ) throughout the country (Musu et al. 
2018). Based on anecdotal accounts and observations in the field, some educators and consultants have noted rates as high as $30 \%$ of their faculty being threatened or assaulted in any given school site in various districts around the nation. One can merely search the Internet for classroom conflicts and physical altercations to get a glimpse into how widespread outbreaks of violence or hostile interactions are throughout the United States' public school systems. Parallel to these ongoing issues is a persistent concern regarding teacher attrition and recruitment - evidenced by numerous media and scholarly reports of teacher shortages at the primary and secondary levels.

There are many ways of theorizing the importance of language in the critical role it plays in the construction of our reality and the transmission of ideas, emotions, and intentions (Chomsky 2002; Civille and Lawless 1986; Hodge and Kress 1993; Widdowson 1989). This particular article does not seek to further the discourse on the theorizing of language, but would rather discuss more directly the implications of harsh language or swearing as a tool for defense, attack, and visibility in the school setting. Focusing specifically on educational environments, the goal of this piece is to shed light on what is both an under examined facet of linguistic interaction and an avoided topic in the academic discourse of educational practice. Much of the current discourse around student expression and conflict focuses on interactions that occur online. This piece seeks to swing some attention back to the realities of the persistent challenges of student-to-adult interaction within the school building itself and recommend steps and techniques to sustain a culture of clear, consistent, and socially just practices.

\section{FRAMEWORK}

This manuscript is written through the lens of a social justice leader and educator. Shields and Mohan (2008) describe social justice education as:

Practices that take into account and are responsive to students' disparate lived experiences, their unequal material and social realities, and their diverse needs - and that, ideally, shape the curriculum, educational strategies, relationships among members of the school community, and create an inclusive learning environment (p. 291).

Written here is a set of practices that might inform educators as to how one might approach heated conflicts while maintaining a strong fidelity to the ethics of a social justice approach. At the core of what is suggested in the following pages is a focus on the responsiveness and relationship-building elements of social justice education through an emphasis on a practical investment in a dialogic approach to student conversation and school discipline.

Borrowing from Paulo Freire's (2000) explanation of the importance of dialogue in education this piece seeks to situate exchanges between adolescents and the educators that work with them within the framework of dialogic leadership (Shields 2005). The importance of dialogue has been discussed for decades in the fields of communication, public relations, philosophy, and psychology as a critical part of human relationship- building and the social construction of meaning (Buber 1958; Frie and Or- 
ange 2013; Heidegger 1962; Jordaan 2009). Liberation pedagogues consider dialogue as a necessary instructional component when teaching for the purposes of challenging oppression. As Freire states "Attempting to liberate the oppressed without their reflective participation in the act of liberation is to treat them as objects which must be saved from a burning building" (2000:16). In the development of relationships, dialogue is a critical mechanism through which common understanding is developed and boundaries are maintained and renegotiated. Shields (2005) notes that:

Dialogue and relationships are not elements that can be selected and discarded at will; rather, they are ways of life-recognitions of the fundamental differences among human beings and of the need to enter into contact, into relational dialogue and sense making (participating with our whole being) with one another.

Shield's notion of dialogic leadership suggests that authority does not have to be enacted from a place of power, but a place of responsibility-a responsibility that stems from the expressed concerns and needs of those to which a leader is accountable, and invested in building positive relationships (2004). Teachers and administrators are in constant dialogue with their students and can use the normalization of such dialogue to more intentionally develop meaning and build understanding when arguments and contentious issues arise regarding school discipline. As Wegerif (2011: 180) clarifies "Robots can interact but their interactions remain in external space. When humans enter into dialogue there is a new space of meaning that opens up between them and includes them within it". Seeking here to move a verbal assault from merely a problematic interaction to an opportunity for mutual reflection, learning, and boundary-reinforcement, the "curse-out" like many other school violations, can be shifted into a moment of meaning. With this in mind, I unpack the potential motives behind the "curse-out" itself and explore specific strategies for addressing student behavior in the larger context of school discipline policy.

\section{THE CONTEXT OF THE “CURSE OUT”}

Merriam-Webster's Dictionary defines the term curse out as a phrasal verb that means "to say angry and offensive words to (someone)" (curse out 2019). If a student feels that cursing out a teacher is their last recourse, it has to be viewed as a major issue. This is not to imply that one incident should mean an automatic transfer out of the school, but I am saying that it is something that staff and leadership must pay close attention to. IT IS NOT OKAY TO CURSE or SWEAR at anyone in a learning environment - especially a teacher. The classroom teacher is responsible for the safety of their students, and as such, if they can be verbally assaulted with no consequence to the student, then all of the students in the room are also at risk.

To be clear, if a teacher gets cursed out in front of their students, once the class resumes, they must express to their classroom the unacceptable nature of the act and why they are frustrated with it. By providing this context, it is then easier to explain why that student is no longer sitting in the classroom (Freire 2000; Shields and Ed- 
wards, 2005). Educators should also try to link the problem to the school values (if the school has identified any) as well as their own expectations of their students (Bohanon et al. 2006; Bradshaw et al. 2009). This response, at the very least, demonstrates that the teacher has an understanding that what just happened is out-of-line and not acceptable at the school. It's always counterintuitive for me when teachers present themselves as the ONLY person in the room that thinks that they found something unacceptable. Specifically, teachers need to consistently and systemically, reinforce a school climate and high behavioral expectations of their students.

We must remember that our students are human beings, socialized with ideas of right and wrong (Haro 2000; Killen and Smetana, 2005; Park and Peterson 2006). For the most part, adolescents can clearly see when something problematic is occurring within a given place or space (Akom 2003; Jackson et al. 2008). However, it is not necessarily their allegiance to ideas of order and appropriateness that I am seeking to point out, but rather their awareness as human beings for what is currently the desire of the group versus a calling out for attention or a demonstration of power and control by one or two individuals. It is in situations of "disruption" (if we define it as an interruption of learning, not a mere act of defiance) that students can identify not only the poor timing and choice of actions by their peers, but also the way in which such behavior represents an ongoing pattern in that student's conduct or is the result of other social and relational issues that appear outside of the classroom.

It is also important to remember that students have more interactions with each other than they do with their teachers. Meaning, teachers can develop a familiarity with their students as students. Youth get to see their peers in a diverse array of settings with only one of which being school. This exposure gives students more of an opportunity to familiarize themselves with each other's personalities and behavioral patterns. When a student acts outside of the expected boundaries of the classroom (whether these have been articulated or not), classmates that already know that student are often the least likely to be surprised. For a variety of reasons, the collective attention in such situations will swing towards how the adult in the room will respond. When an educator acts in a way that gives the impression that something unacceptable is tolerable, students are sent the message that not only is that teacher "weak", but they also lack the social awareness and necessary skills to protect the classroom.

There are numerous opportunities in our schools for exchanges of disrespect and profanity to occur. Small disagreements can turn into fights if not intervened upon. These heated verbal and/or physical conflicts often result in teachers and staff intervening to deescalate the situation. It is a prime opportunity for a "curse-out". "You'll hear things like "get the f--k off me!" or "f--k you, don't touch me!" or the classic " $\mathrm{f}-\mathrm{-k}$ you b---h!" seemingly hurled out into the general public and to any and every one in these situations by frustrated students.

In this piece, I am not referring specifically to the profanity or "cussing” itself, but what the curse-out represents in student-to-teacher dialogue. When students verbally assault educators it is typically in response to a request or directive of some sort given by a teacher, administrator, or staff person. It's not necessarily a counterpunch but it may also happen in that way. Researchers have examined the ways in which swearing 
plays a significant role in society at large (Bergen 2016), and can serve as a mechanism for marking relationships (Stapleton 2003; Winters and Duck 2001), as well as shaping public perception of oneself (DeFrank and Kahlbaugh 2019). Many of us are quite familiar with swearing as an almost "knee-jerk" reaction to pain and - depending on the cultural context - a quite routine form of expressing emotions such as anger, delight, excitement, or sadness (Jay and Janschewitz 2008).

For students, sometimes it can be a quick "f--k that" to a request to move one's seat or to step outside the classroom. Other times it can be a "f--k you" or "I ain't doin s-t" to a request to come and engage with an instructor in a hallway or to change clothes into more appropriate attire. It can get a little more technical when it comes in the form of personal possessions that have been confiscated like cell phones or iPods "you better give me my f--kin phone” or “you ain’t keepin my s--t!"

\section{What to do if you are the teacher}

So what do you do when you are on the receiving end of a verbal assault of profanity? Below, I outline four key steps to responding.

1. Stay calm. It is important to remain calm, but without being patronizing (like a boss, with patience). Although you have the power to wield over the student, that won't be beneficial to either of you in the moment. What the student(s) need to see is a confident adult that is clear-minded and strong enough to keep the space safe.

2. Address the cursing immediately. Without delay, respond promptly and inquire about the behavior. Ask "what was that?" or "what just happened, did I miss something?" This calls attention to the act as a disrespectful disruption that they caused, but must reflect upon - not just an offense on you.

3. Help the student clarify their intent while you clarify yours. For example, consider asking the following questions: What would make you talk to me like that? Is it really this? What did I do to prompt this behavior? You can either start or follow these questions by reminding the student of your purpose as their teacher. For example, this may sound like the following: "I am here for one purpose-your education and development. I can't do that with our folks feeling like they can't function here in a healthy way. It can't be healthy with folks cursing each other out every time they get upset. It is my job to make sure that folks are not able to threaten or intimidate people here and there is no way that I would let someone talk to you in that way and get away with it". "So, tell me what is going on so we can resolve this". What would make you talk to me like that? Is it really this? What did I do?" If the student is unable to calm down after this-it is time for them to go to the office.

4. Remind the student of the school's/ community's standards. It is important for the student to know and understand that such an inappropriate act is not our standard, nor the historical standard of their community or communities moving towards liberation and humanization. It may sound like this, "As a school that has respect for you, this community, and the history of those who struggle to be seen and valued as human beings, we cannot accept this type of behavior. We know that you are better than this and that what you represent in this world is too important for this to be your 
standard or ours as a school. If something is causing you to act this way, let me know so I can help and support you. But, we will never accept this as your standard". "So, what is going on?" What would make you talk to me like that? Is it really this? What did I do?

After these steps, the student needs to go to the office. The second half of the piece discusses steps that need to be taken when the student goes to the office and how these issues of student expectations and school climate and values need to be addressed from the administrator's perspective.

\section{What to do as an administrator}

1. Preparing for the office visit. When the student and teacher arrive at the office, the Administrator should already have received a call from the teacher as to whom is coming to the office, and why they are coming. If this does not happen, the student, security staff, or the teacher should bring a referral with the basic information of what happened for the administrator to review with the student. This can often take some time as teachers have an entire class to worry about and focus on. No stress, a talented administrator can get the "low down" from the basic information form, the original call, and the student themselves.

2. Know your staff. As an administrator, it is in these moments when knowing your staff and the various styles of your teachers, is important. Random, frequent, classroom visits - even for just 2 minutes - can help give an administrator an idea of the environment a teacher creates in their classroom. The students' body language, collective concentration, amount of classroom movement, and teacher's behavior can vary day-to-day so frequent visits throughout the year (6-7 times per class) can give an administrator a better idea of how the teacher interacts with students. Close attention to how teachers behave in general is important to know as well.

3. Participate in professional development. Professional development that targets key social issues such as race, class, gender, sexual orientation, privilege, and personal histories can give an administrator a clearer idea of how their staff members frame issues and, at the very least, articulate how staff is expected to frame issues. All of this gives the administrator a foundation from which to work with the teacher, student, and their family when violations of school policy occur as you can vouch for your staff's integrity and intent while also being prepared to help your staff improve their practice to avoid these issues in the future.

4. Ask the "What happened" question. This question is critical to the process. A school leader not only represents the interests of the school, but they also model the ideal expectations of behavior for students. So the disciplinary session has to begin with the administrator listening. I'll write more on the active listening needed here, but the point is that you are searching for the trigger so that you can understand what set the student off. This process is not intended to pathologize the student, but rather, to dig within yourself to relate to them in that scenario. For example, consider what would trigger you in that situation?

As educators, we want to know what happened on a scope that informs us of what 
the parties understand as natural reactions, personal violations, and acceptable acts of atonement within a socialized, rational communal notion of morality. This information also helps us see our students as actors in a social world that exists outside the school while influencing interactions inside the school. Such a perspective, absent of value judgments as to the sanity of communal beliefs and habits, helps frame the disciplinary dialogue with students as an instructional one.

5. Engage in active listening. As administrators, it is also important to use active listening skills with the student. Pay attention to the body language and tone of every word. Ask for clarification as the story develops to make sure you understand the roles and relationships of each player in the story. This is helpful as your clarifying questions help the student take a step back and see the progression of events.

6. Validate the student's emotion as real. As the student explains their perspective and feelings, be sure to validate how they feel. Question their interpretation of the triggering act. This questioning does not mean that they are wrong. You mainly want to understand how your students respond to different elements of teacher behavior. For example, students can become upset when they feel that they are being overlooked or treated as if they are invisible. Such feelings have a string history as embedded micro aggressions within relational race, class, and gender power dynamics. In a school setting, this can often occur when a teacher has not sufficiently articulated the ways in which students will have an opportunity to engage in the class discussion. This can lead to some students raising their hands and being interrupted by students calling out; or, students calling out because the boundaries for such conversation rituals have been inconsistently upheld.

If the student's interpretation of the interaction is reasonable, it'll provide a great opportunity to have an instructional moment between you and your teacher. If you find it common in student-teacher conflicts, you may have a good topic for professional development training or possibly a town hall meeting, assembly, or advisory discussion with the student body. Sometimes it can be as simple as teachers missing a raised hand as they attend to the speaker rotation. No matter the reason, it is a common way in which students experience alienation and silencing in school environments. These actions can enhance the sense of invisibility that large school populations can inherently produce.

As an educator seeking to utilize the situation as a learning opportunity, it is important to recognize the possibilities in framing these interactions as such. Affirming the student's initial emotional response can lead to a discussion about other vantage points. It may sound like this: "I understand how that feels. I would be angry too!" Then you can proceed with questions like: "Do you think it was personal, or did the teacher just seem like they were in a rush?" Questions like this can get a student to think about the responsibilities of a teacher as difficult and the teacher as an imperfect being. It also sets a foundation for a great conversation between the student and teacher regarding what happened without the student viewing the incident as an attack, but a problematic oversight that should not happen again.

7. Rebuke student behavior as inconsistent with the direction of the school and its mission. This is when you must teach as an administrator. Students have to 
understand the value of stopping and thinking, especially when they are agitated. And administrators have to be clear about the alternative behaviors that students should exhibit when they are upset. What students should do is as critical to understand as what they shouldn't do and the disciplinary conversation with an administrator or teacher should always articulate the expected alternative behaviors within the school community (based on the principles and values of the school).

It is also important to entertain any suggestions from students as to how staff might alter their reactions to student behavior. This does not mean that students lead your professional development design, but sometimes, a student will give a teacher or administrator a nugget of advice that provides them with an important step to improved practice.

8. Work towards an analysis of teacher and/or staff intent. As educators interested in social justice, we are always conscious of the inherent power dynamic in the teacher-student relationship. Sometimes, adults want to soften the prominence of the dynamic by acting as a friend or a therapist. Instead of doing this, it's always helpful to discuss the intent and reasoning behind such decisions. This type of conversation shifts the discussion from one of obedience or indebtedness to one of understanding. It also gives the student an opportunity to engage in debate as to how the adult manifested the intent (and whether or not there's a better way). This practice affirms a safe space in which both parties can discuss the reasoning of the actions taken. Prompts to foster improved understanding may sound like this: "Do you really think the teacher meant it that way?"; "What if the teacher was just trying to do this instead?"; "How would you act if you were trying to communicate with folks and someone does what you did to interrupt?" These questions are critical to ask as we encourage students to read body language, reflect on the patterns of others, and set their interactions in a context.

9. Stay on topic - the real topic - their holistic education. This is not just about school, but life preparation. It is important for the dialogue with students to be connected to the larger issue of their holistic education and development and not just about the cursing incident. Students need to understand how cursing is symbolic of a value system that is counter to the values of the school. The administrator needs to emphasize that they and their teachers have high expectations for the student, not only in learning and exams, but also in their overall life.

10. Ask "what can I do to help this not happen again?" - We play different positions and roles, but students need to understand that we are on the same team and have the same goals. Students and their families need to know that someone is in charge and that they have what is right on their minds as well as what is best for the student body.

11. Give them an honorable opportunity for atonement. This varies from student to student, but in some way students need to acknowledge that they have heard and understand (not necessarily agree with) your thoughts on: (a) Why their response was a problem; (b) Why you responded the way you did (e.g. you can emphasize the importance of education to the individual and the class); and (c) Your recommendations on a better way to handle the situation in the future. The student response may 
be an apology or a statement that conveys a comprehension of the various complexities that have been presented by you in the discussion. This step is not a substitute for a consequence, but rather a key opportunity for the student to process what they have heard and learned in the teachable moment.

12. Giving out the Consequence. Remind the student that they made a mistake and that mistakes happen. But clarify that there is a difference between making a mistake and being a mistake. A school for social justice should be an institution that trains youth to challenge oppression in its conventional and internalized forms. Your students must be reminded that you are interested in having a school that works well for each student and that you will be excited to see them upon their return from their suspension. But, simply put: "We don't do that here and we know that you know why. So get it together and we'll do our part to help you grow."

\section{CONCLUSION - IT IS ALWAYS A TEST}

Students might be testing your courage, wisdom, or concern for the student body. They are usually just doing what teenagers do-testing the location and rigidness of the stated boundaries (Baumrind 2005; Mayseless and Scharf 2009). Often, this is a secondary intent and it can be at the subconscious or unconscious level in many cases. It is always a challenge to the school's ethics and the courage of those that choose the path of wisdom over oppression. Intentional or not, it is a test and no matter what the student's intent might be it is certainly a test in the eyes of everyone else who is aware of the situation. These moments are ones in which everyone is waiting to see if the school leader really walks the talk. One glaring inconsistency or show of favoritism will inevitably send the message that: (a) there's a randomness to the discipline structure of the school; or, (b) one student does come before the whole school and due to this, you can watch your leadership ability decrease significantly in a matter of days.

Faith and trust are a leader's best assets (Greenleaf and Spears 2002; Joseph and Winston 2005; Tschannen-Moran 2014). As teachers are the leaders of the classroom, they must work to authentically build trusting relationships with students and their families. Notice I am not saying "love" - but trust - and in communities with histories of violence in their streets, trust it built with consistency and safety. People have to believe that the leader or teacher of a school has the skills to do the job, but they have to have faith that they will do the job. This helps the community lend some sort of support to get it done. So, in order to get high marks while being constantly tested, a school educator must be consistently courageous, humble, thoughtful, clear, and caring. These are the units of analysis upon which these tests are based, so when it comes to discipline issues, it is always about how you handle it.

FUNDING: This research received no external funding.

CONFLICT OF INTEREST: The author declares no conflict of interest. 


\section{REFERENCES}

Akom, Antwi A. 2003. “Reexamining Resistance as Oppositional Behavior: The Nation of Islam and the Creation of a Black Achievement Ideology.” Sociology of Education 76(4): 305-325.

Baumrind, Diana. 2005. "Patterns of Parental Authority and Adolescent Autonomy." New Directions for Child and Adolescent Development 2005(108): 61-69. https:// doi.org/10.1002/cd.128

Bergen, Benjamin K. 2016. What the F: What Swearing Reveals about our Language, our Brains, and Ourselves. New York: Basic Books.

Bohanon, Hank, Pamela Fenning, Kelly L. Carney, Myoung J. Minnis-Kim, Sarah Anderson-Harriss, Kristyn B. Moroz, Kira J. Hicks, Beverly B. Kasper, Carrie Culos and Wayne Sailor. 2006. "Schoolwide Application of Positive Behavior Support in an Urban High School: A Case Study.” Journal of Positive Behavior Interventions 8(3): 131-145. https://doi.org/10.1177/10983007060080030201

Bradshaw, Catherine P., Christine W. Koth, Leslie A. Thornton and Philip J. Leaf. 2009. “Altering School Climate through School-Wide Positive Behavioral Interventions and Supports: Findings from a Group-Randomized Effectiveness Trial.” Prevention Science 10(2):100-115.

Chomsky, Noam and Chomsky Noam. 2002. On Nature and Language. Cambridge: Cambridge University Press.

Civille, Gail V. and Harry T. Lawless. 1986. “The Importance of Language in Describing Perceptions.” Journal of Sensory Studies 1(3-4): 203-215. https://doi.org/10.1111/ j.1745-459X.1986.tb00174.X

curse out. 2019. Retrieved May 12, 2019 (https://www.merriam-webster.com/dictionary/curse\%20out).

DeFrank, Melanie and Patricia Kahlbaugh. 2019. "Language Choice Matters: When Profanity Affects how People are Judged." Journal of Language and Social Psychology 38(1): 126-141.

Freire, Paulo. 2000. Pedagogy of the Oppressed. 30th Anniv. Ed. New York: Continuum 35.

Frie, Roger and Donna Orange. 2013. Beyond Postmodernism: New Dimensions in Clinical Theory and Practice. New York: Routledge.

Greenleaf, Robert K. 2002. Servant Leadership: A Journey into the Nature of Legitimate Power and Greatness. New York: Paulist Press.

Harro, Bobble. 2000. “The Cycle of Socialization.” Pp. 15-21 in Readings for Diversity and Social Justice, edited by M. Adams, W. Blumenfeld, R. Castaneda, H. Hackman, M. Peters, and X. Zuniga. New York: Routledge.

Hodge, Robert and Gunther R. Kress. 1993. Language as Ideology. London: Routledge. Jackson, Linda A., Yong Zhao, Wei Qiu, Anthony Kolenic III, Hiram E. Fitzgerald, Rena Harold and Alexander Von Eye. 2008. "Cultural Differences in Morality in the Real and Virtual Worlds: A Comparison of Chinese and US Youth.” CyberPsychology \& Behavior 11(3): 279-286.

Jay, Timothy and Kristin Janschewitz. 2008. “The Pragmatics of Swearing.” Journal of 
Politeness Research. Language, Behaviour, Culture 4(2):267-288.

Jordaan, Eduard. 2009. “Dialogic Cosmopolitanism and Global Justice.” International Studies Review 11(4): 736-748.

Joseph, Errol E. and Bruce E. Winston. 2005. "A Correlation of Servant Leadership, Leader Trust, and Organizational Trust.” Leadership \& Organization Development Journal 26(1): 6-22.

Killen, Melanie and J. G. Smetana. 2005. Handbook of Moral Development. Manwah, N.J.: Lawrence Erlbaum Associates.

Mayseless, Ofra and Miri Scharf. 2009. "Too Close for Comfort: Inadequate Boundaries with Parents and Individuation in Late Adolescent Girls.” American Journal of Orthopsychiatry 79(2): 191-202.

Musu, Lauren, Anlan Zhang, Ke Wang, Jizhi Zhang and Barbara Oudekerk. 2019. Indicators of School Crime and Safety: 2018. U.S. Department of Education. Washington: NCES, IES.

Park, Nansook and Christopher Peterson. 2006. "Moral Competence and Character Strengths among Adolescents: The Development and Validation of the Values in Action Inventory of Strengths for Youth.” Journal of Adolescence 29(6): 891-909.

Shields, Carolyn M. and Mark M. Edwards. 2005. Dialogue is Not just Talk: A New Ground for Educational Leadership. New York, NY: Peter Lang.

Shields, Carolyn M. and Erica J. Mohan. 2008. "High-quality Education for all Students: Putting Social Justice at its Heart.” Teacher Development 12(4): 289-300.

Stapleton, Karyn. 2003. "Gender and Swearing: A Community Practice.” Women and Language 26(2): 22-33.

Stephens, Richard, John Atkins and Andrew Kingston. 2009. "Swearing as a Response to Pain.” Neuroreport 20(12): 1056-1060.

Tschannen-Moran, Megan. 2014. Trust Matters: Leadership for Successful Schools. San Francisco: John Wiley \& Sons.

Widdowson, Henry G. 1989. “Knowledge of Language and Ability for Use.” Applied Linguistics 10(2): 128-137.

Winters, Alaina M. and Steve Duck. 2001. "You****!: Swearing as an Aversive and a Relational Activity.” Pp. 59-77 in Behaving badly: Aversive behaviors in interpersonal relationships, edited by R. M. Kowlaski. American Psychological Association. https://doi.org/10.1037/10365-003

\section{BIOGRAPHICAL NOTE}

Darrick Smith is associate professor of Leadership Studies at University of San Francisco, USA.

OPEN ACCESS: This article is distributed under the terms of the Creative Commons Attribution Non-commercial License (CC BY-NC 4.0) which permits any non-commercial use, and reproduction in any medium, provided the original author(s) and source are credited. 
